\section{Influenza vaccination in non-institutionalized elderly: a population-based study in a medium-sized city in Southern Brazil}

\author{
Vacinação contra a gripe em idosos não- \\ institucionalizados: estudo de base populacional \\ em município de médio porte do Sul do Brasil
}

\author{
1 Programa de Pós-graduação \\ em Saúde Coletiva, \\ Universidade Estadual de \\ Londrina, Londrina, Brasil. \\ Correspondence \\ R. M. Dip \\ Departamento de Clínica \\ Médica, Programa de \\ Pós-graduação em Saúde \\ Coletiva, Universidade \\ Estadual de Londrina. \\ Rua Pistóia 287, Londrina, $P R$ \\ 86020-450, Brasil. \\ renatadip@yahoo.com.br
}

\begin{abstract}
Vaccination is the most effective measure to prevent the complications of influenza. This population-based study aimed to estimate influenza vaccine coverage in non-institutionalized elderly, analyze the factors involved in lack of influenza vaccine uptake, and identify post-vaccination adverse effects. The study population lived in an urban neighborhood in Southern Brazil, and the sample consisted of 425 elderly. A total of 396 elderly individuals (age 60-95 years) were interviewed. Although 100\% of the sample reported knowing about the vaccine, only $5.3 \%$ referred to their personal doctor as the source of information. Among elders that had not received the vaccine, 83.2\% were explicit about not wanting to take it. The main reasons were fear of adverse effects and disbelief in the vaccine's effectiveness. However, the actual prevalence of adverse effects was low. Age, smoking, and lack of a doctor's appointment in the previous year were independently associated with vaccine non-compliance. The results show that improvements are needed in the immunization campaign, especially targeting elders less than 70 years of age and smokers.
\end{abstract}

Influenza Vaccines; Immunization Coverage; Aged
Renata Maciulis Dip 1

Marcos A. S. Cabrera ${ }^{1}$

\section{Introduction}

Influenza has such a huge impact that it is estimated to be the infectious cause with the greatest morbidity and mortality in the world 1 . The spectrum of influenza infection ranges from mild, short-lasting symptoms to more severe complications with death as the outcome 2 . In non-pandemic periods, influenza-related complications and deaths occur mainly in the elderly and in patients with chronic illnesses like cardiac failure, diabetes, and chronic lung disease. Most individuals with these diseases belong to the more advanced age groups.

Thus, the elderly are the group in which influenza potentially causes the most harm (NguyenVan-Tam, 1998, apud Nguyen-Van-Tam \& Hampson ${ }^{3}$ ). In the United States, influenza accounts for some 226 thousand hospitalizations and 50 deaths yearly 4 . More than $90 \%$ of the deaths occur in the elderly 5.

The prevention, control, and treatment of this potentially lethal disease are based on antiviral agents, symptomatic medication, and vaccines 6 . Vaccination is currently the most effective means to prevent the consequences of influenza 7,8.

The main objective of vaccination in the elderly is not to reduce the incidence of flu itself, but to reduce the risk of complications in more vulnerable individuals ${ }^{9}$. According to a recent meta-analysis by Jefferson et al. ${ }^{10}$, in institutionalized individuals, although the vaccine did not 
prove effective for preventing the flu, it was effective in the prevention of pneumonia, hospitalization, and the reduction of deaths from influenza, pneumonia, and all causes.

There are also other benefits from vaccination, like a decrease in hospitalizations due to cardiac and cerebrovascular diseases 11 .

Although some recent articles suggest that the vaccine's efficacy may be overestimated, this issue remains controversial and requires further study 12,13 .

Although Brazil's national target of $70 \%$ vaccine coverage has been reached, coverage is inadequate in certain groups of elderly. This lack of vaccine uptake has been studied by various Brazilian authors, who have identified the following factors: age 14,15,16, schooling 15,16, and comorbidities 14,15,16. Non-compliance was explained by some myths related to post-vaccination adverse events and even lack of belief in the vaccine 17 .

The objectives of the current study were to analyze influenza vaccination in non-institutionalized elderly in the catchment area of a primary healthcare unit in southern Brazil in terms of vaccine coverage, post-vaccination adverse events, factors associated with lack of uptake, and reasons claimed for non-compliance, seeking approaches in order for a larger share of the population to benefit from the vaccine and the resulting improved quality of life.

\section{Methods}

\section{Study design}

This was an individual analytical, populationbased cross-sectional study.

\section{Study population and area}

The current study was conducted in the Municipality of Londrina, State of Paraná, Brazil, in the catchment area of a primary healthcare unit covered by the Family Health Program (FHP).

Londrina is located in the South of Brazil, in northern Paraná State. The population is approximately 505,184 (IBGE. Censo Demográfico de 2000. http:/ /www.ibge.gov.br). The target area is located in the central area of the city and was selected due to its high concentration of elderly and socioeconomic diversity.

The study sample consisted of individuals 60 years or older residing in this area. The sample was defined using census tracts specified by the Brazilian Institute of Geography and Statistics (IBGE), which consist of micro-areas for which census data are available 18 . Thus, the total popu- lation of the study area was estimated at 12,016, including 984 elderly.

The sample was calculated using Epi Info version 3.4.1 (Centers for Disease Control and Prevention, Atlanta, U.S.A.), considering the same expected vaccine uptake rate as in the last vaccination campaign, 2006: $84.7 \%$. The margin of error was $3 \%$, with a $95 \%$ confidence interval. The calculated value added $20 \%$ losses, resulting in a sample of 425 individuals (with an expected $45 \%$ men and 55\% women) 18 .

The sample was stratified proportionally according to gender and the number of elderly in each tract, with the definition of quotas of elderly to be filled in each census tract.

\section{Data collection}

To train the research team and adjust the form, a pilot study was held with elderly in a neighborhood with similar characteristics to those of the final target neighborhood.

Data were collected using a household interview, in June-July 2007, beginning three weeks after the conclusion of the vaccination campaign.

The questions were answered by the elderly individual or his or her caregiver. Random routes were traced on the maps for each census tract in order to determine the order of households to be surveyed. If there was more than one elderly individual in the same household, a coin was flipped to include only one in the survey (this was the only exclusion criterion in the study). If the selected elderly individual was not present in the household at the time, a new visit was scheduled.

Elderly individuals not found after four attempted visits were considered sample losses.

\section{Study variables}

The study's dependent variable was non-compliance with the vaccine in the current year (2007). Vaccine non-compliance was defined as the elderly subject (or caregiver) reporting that the subject had not been vaccinated 19 .

The socio-demographic variables were: age in years; low schooling (fewer than five years); marital status (living versus not living with spouse/ partner); currently working; low economic status, or strata D and E (Associação Brasileira de Empresas de Pesquisa. Critério de classificação econômica Brasil 2003. http://www.abep.org.br, accessed on 22/Sep/2006).

Comorbidity variables were: completely bedridden; hospitalization during the previous year; and report of the following diagnoses: systemic arterial hypertension, diabetes, cardiovascular diseases, chronic lung disease, and depression. 
Medical care variables were: date of last medical consultation; usual place for medical consultations (contact with primary healthcare unit versus no such contact).

Lifestyle variables were: regular physical activity (at least 30 minutes at least three times a week); frequency of alcohol consumption; smoking (currently smokes versus never smoked or stopped at least a year previously).

Vaccine-related variables were: compliance versus non-compliance in 2007; source of knowledge on the vaccine; place of vaccination (primary healthcare unit or private clinic); reasons for non-compliance (didn't want, couldn't, didn't know about the campaign); post-vaccination adverse events. The elderly were also asked why they did not want to (or could not) be vaccinated, and the answers were categorized by the interviewer.

Side effects from the influenza vaccine only include symptoms occurring up to 48 hours after vaccination 7 . However, among the general population in Brazil there is a widespread false notion that the vaccine is highly prone to causing reactions ${ }^{17}$. In order to better evaluate this common misconception, the elderly were asked about adverse events and the time transpired until their occurrence. The answers were categorized in symptoms that began up to two weeks after vaccination and more than two weeks after.

\section{Statistical Analysis}

The data were keyed into a database created with Epi Info version 3.4.1.

A descriptive analysis of the variables was performed by gender, using the chi-square test and Fisher's exact test when necessary.

A bivariate analysis was performed between all the independent variables and the dependent variable, namely vaccine non-compliance in 2007.

The multivariate model used in the logistic regression analysis was obtained in relation to the variable vaccine non-compliance in 2007 with the inclusion of the gender variable and the variables that presented a $\mathrm{p}$ value less than 0.20 in the bivariate analysis.

A 95\% significance level was adopted in all the tests.

\section{Ethical issues}

The study was approved by the Institutional Review Board for Research Involving Human Beings at the State University in Londrina. Prior to the interviews, the elderly subjects received an explanation of the research objectives and were asked to sign the informed consent form.

\section{Results}

\section{Characterization of the study population}

A total of 396 elderly subjects were interviewed, among the projected sample of 425 . It was not possible to interview 29 individuals (6.8\%), i.e., 16 men and 13 women, who were classified as losses. Of these, 10 elderly were not located in their homes and 19 refused to participate in the study.

Thus, the sample consisted of 222 women and 174 men. The mean age of the study population was 72.1 years (standard deviation $-\mathrm{SD}=7.9$; median 71 years), with no differences between the genders in terms of age brackets. No difference was observed between the genders in terms of economic class (Table 1).

More men than women were married, and more men were in the paid workforce $(p<0.001)$. Women had less schooling than men. Among the most frequent comorbidities, women showed a higher prevalence of systemic arterial hypertension and depression. More men than women reported the lack of a medical consultation in the previous year $(\mathrm{p}<0.001)$ (Table 1$)$.

As for lifestyle, no statistically significant gender differences were found for either regular physical activity or smoking. However, more men reported daily consumption of alcoholic beverages $(\mathrm{p}<0.001)$.

As for the source of information on the vaccine, all the elderly interviewees reported having heard of it, and the most widely cited source was television (66.4\%). The second most frequent source was friends $(25.3 \%)$. Nurses and doctors were cited by only $10.4 \%$ and $5.3 \%$ of the interviewees, respectively.

Vaccine coverage was 73\%, with 289 elderly vaccinated (95\%CI: 68.3-77.2).

The most widely reported place for vaccination was the primary healthcare unit $(91 \%)$, as compared to $7 \%$ at home and $2.4 \%$ in private clinics.

Among the vaccinated elderly, 251 (86.8\%) reported no adverse events following vaccination. Flu-like symptoms up to two weeks after vaccination were reported by $6.6 \%$ of the elderly. Another 6\% reported flu-like symptoms more than two weeks after receiving the vaccine. No other post-vaccination adverse reactions were reported.

The main reason cited by elderly subjects for non-compliance was that they did not want to receive the vaccine (83.2\% of the unvaccinated). Other reasons were: not being able to receive the vaccine (15.9\%) and not knowing that it was vaccination time $(0.9 \%)$. 
Table 1

Distribution of socio-demographic variables among a sample of elderly in relation to gender. Londrina, Paraná State, Brazil, 2007.

\begin{tabular}{|c|c|c|c|c|c|c|c|}
\hline \multirow[t]{3}{*}{ Factor } & \multicolumn{4}{|c|}{ Gender } & \multicolumn{2}{|c|}{ Total } & \multirow[t]{3}{*}{$p$ value } \\
\hline & \multicolumn{2}{|c|}{ Female } & \multicolumn{2}{|c|}{ Male } & \multirow[b]{2}{*}{$\mathrm{n}$} & \multirow[b]{2}{*}{$\%$} & \\
\hline & $\mathrm{n}$ & $\%$ & $\mathrm{n}$ & $\%$ & & & \\
\hline Gender & 222 & 56.1 & 174 & 43.9 & 396 & 100.0 & \\
\hline \multicolumn{8}{|l|}{ Age bracket (years) } \\
\hline $60-69$ & 99 & 44.6 & 78 & 44.8 & 177 & 44.7 & 0.96 \\
\hline$\geq 70$ & 123 & 55.4 & 96 & 55.2 & 219 & 55.3 & \\
\hline \multicolumn{8}{|l|}{ Schooling (years) } \\
\hline$<5$ & 140 & 63.1 & 92 & 52.9 & 232 & 58.6 & 0.04 \\
\hline$\geq 5$ & 82 & 36.9 & 82 & 47.1 & 164 & 41.4 & \\
\hline \multicolumn{8}{|l|}{ Economic class * } \\
\hline$A, B$, or $C$ & 180 & 81.1 & 148 & 85.1 & 328 & 82.8 & 0.30 \\
\hline D or E (low) & 42 & 18.9 & 26 & 14.9 & 68 & 17.2 & \\
\hline \multicolumn{8}{|l|}{ Currently in the workforce } \\
\hline Yes & 40 & 18.0 & 77 & 44.3 & 117 & 29.5 & $<0.001$ \\
\hline No & 182 & 82.0 & 97 & 55.7 & 279 & 70.5 & \\
\hline \multicolumn{8}{|l|}{ Marital status } \\
\hline Married & 79 & 35.6 & 129 & 74.1 & 208 & 52.5 & $<0.001$ \\
\hline Other & 143 & 64.4 & 45 & 25.9 & 188 & 47.5 & \\
\hline \multicolumn{8}{|l|}{ Arterial hypertension } \\
\hline Yes & 147 & 66.2 & 95 & 54.6 & 242 & 61.1 & 0.02 \\
\hline No & 75 & 33.8 & 79 & 45.4 & 154 & 38.9 & \\
\hline \multicolumn{8}{|l|}{ Diabetes } \\
\hline Yes & 37 & 16.7 & 33 & 19.0 & 70 & 17.7 & 0.55 \\
\hline No & 185 & 83.3 & 141 & 81.0 & 326 & 82.3 & \\
\hline \multicolumn{8}{|l|}{ Chronic lung disease } \\
\hline Yes & 30 & 13.5 & 37 & 21.3 & 67 & 16.9 & 0.04 \\
\hline No & 192 & 86.5 & 137 & 78.7 & 329 & 83.1 & \\
\hline \multicolumn{8}{|l|}{ Depression } \\
\hline Yes & 48 & 21.6 & 15 & 8.6 & 63 & 15.9 & $<0.001$ \\
\hline No & 174 & 78.4 & 159 & 91.4 & 333 & 84.1 & \\
\hline \multicolumn{8}{|l|}{ Cardiovascular disease } \\
\hline Yes & 75 & 33.8 & 57 & 32.8 & 132 & 33.3 & 0.83 \\
\hline No & 147 & 66.2 & 117 & 67.2 & 264 & 66.7 & \\
\hline \multicolumn{8}{|l|}{ Bedridden } \\
\hline Yes & 6 & 2.7 & 1 & 0.6 & 7 & 1.8 & 0.14 \#\# \\
\hline No & 216 & 97.3 & 173 & 99.4 & 389 & 98.2 & \\
\hline \multicolumn{8}{|l|}{ Last medical consultation } \\
\hline 1 year previously or less & 211 & 95.0 & 148 & 85.1 & 359 & 90.7 & $<0.001$ \\
\hline$\geq 1$ year previously & 11 & 5.0 & 26 & 14.9 & 37 & 9.3 & \\
\hline \multicolumn{8}{|l|}{ Place, medical appointment } \\
\hline Private practice only & 109 & 49.1 & 92 & 52.9 & 201 & 50.8 & 0.46 \\
\hline Public healthcare service ** & 113 & 50.9 & 82 & 47.1 & 195 & 49.2 & \\
\hline Hospitalization in previous year & & & & & & & \\
\hline Yes & 37 & 16.7 & 31 & 17.8 & 68 & 17.2 & 0.76 \\
\hline No & 185 & 83.3 & 143 & 82.2 & 328 & 82.8 & \\
\hline Physical activity & & & & & & & \\
\hline 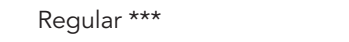 & 66 & 29.7 & 66 & 37.9 & 132 & 33.3 & 0.09 \\
\hline Not regular & 156 & 70.3 & 108 & 62.1 & 264 & 66.7 & \\
\hline
\end{tabular}

(continues) 
Table 1 (continued)

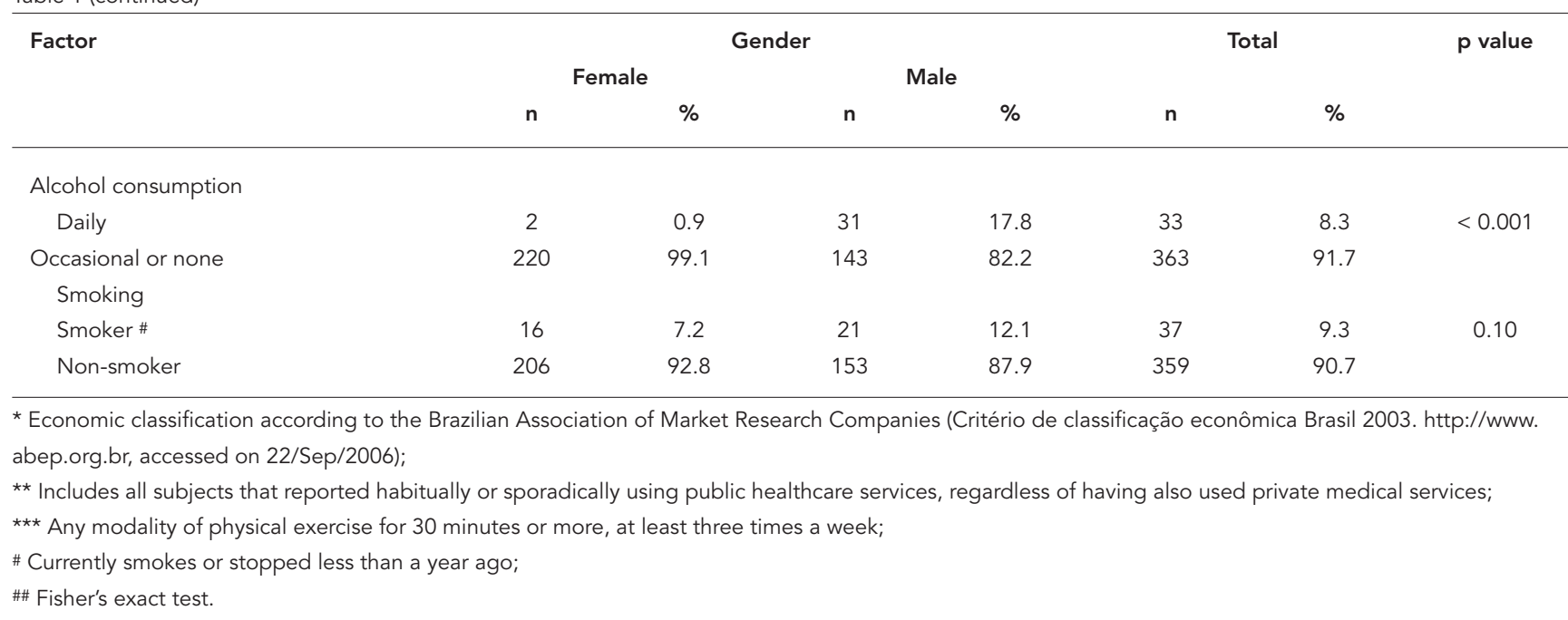

When investigating the reasons for the elderly not wanting to be vaccinated, $41.1 \%$ of the unvaccinated reported a history of reactions to previous vaccines or fear of reactions in case they were vaccinated. The second most widely cited reason was never having had influenza and their related belief that they did not need the vaccine (21.5\%). Other reasons are listed in Table 2.

Table 3 shows the bivariate analysis between socio-demographic, morbidity, healthcare-related, and lifestyle variables and vaccine non-compliance.

The multivariate analysis of factors associated with vaccine non-compliance was obtained with the dependent variable vaccine compliance and the following independent variables: gender, age less than 70 years, low economic class, less than five years of schooling, last medical consultation more than a year previously, and smoking. Age, smoking, and time transpired since the last medical consultation were independently associated with non-vaccination in this analysis (Table 4).

\section{Discussion}

The findings with this elderly population show a high proportion of unvaccinated individuals and point to some factors associated with non-compliance. The prevalence of adverse events was low, and the main reason for non-compliance was that some elderly individuals did not want to be vaccinated.

A positive aspect of the sample was its diversity, guaranteed by the selected neighborhood and study design. The selected sample of 425
Table 2

Reasons cited for influenza vaccine non-compliance in 2007. Londrina, Paraná State, Brazil.

\begin{tabular}{lcc}
\hline Reason & $\mathbf{n}$ & $\%$ \\
\hline Did not want to be vaccinated & & \\
Prior reaction to vaccine or fear of adverse event & 44 & 41.2 \\
Did not have flu/Did not need the vaccine & 23 & 21.6 \\
Disbelief in vaccine's efficacy & 5 & 4.7 \\
Fear of pain at needle site & 4 & 3.7 \\
Other & 13 & 12.1 \\
Could not be vaccinated & & 0.9 \\
Allergy to egg & 1 & 6.5 \\
Was ill & 7 & 3.7 \\
Forgot the deadline & 4 & 4.7 \\
Other & 5 & 0.9 \\
Did not know the reason & 1 & \\
\hline
\end{tabular}

elderly subjects is representative of the 984 elderly in the area. The IBGE (National Census Bureau) estimates the proportion of elderly at $9.3 \%$ in Londrina 18 and $8.2 \%$ in the study area. Since this was a population-based study, the sample is representative of a population of non-institutionalized elderly.

When comparing the genders for the study characteristics, the age brackets were represented homogeneously between men and women. However, some differences were found in other characteristics and should be considered. Women showed lower schooling, and proportionally more men were in the workforce and married. These differences between men and women should be taken into account in epidemiological 
Table 3

Bivariate analysis of influenza vaccine compliance and related factors in the elderly. Londrina, Paraná State, Brazil, 2007.

\begin{tabular}{|c|c|c|c|c|c|}
\hline \multirow[t]{2}{*}{ Variable } & \multicolumn{2}{|c|}{ Vaccine compliance } & \multicolumn{2}{|c|}{ Non-compliance } & \multirow[t]{2}{*}{$p$ value } \\
\hline & $\mathrm{n}$ & $\%$ & $\mathrm{n}$ & $\%$ & \\
\hline \multicolumn{6}{|l|}{ Gender } \\
\hline Male & 132 & 75.9 & 42 & 24.1 & 0.25 \\
\hline Female & 157 & 70.7 & 65 & 29.3 & \\
\hline \multicolumn{6}{|l|}{ Age (years) } \\
\hline $60-69$ & 113 & 63.8 & 64 & 36.2 & $<0.001$ \\
\hline$\geq 70$ & 176 & 80.4 & 43 & 19.6 & \\
\hline \multicolumn{6}{|l|}{ Schooling (years) } \\
\hline$<5$ & 179 & 77.2 & 53 & 22.8 & 0.03 \\
\hline$\geq 5$ & 110 & 67.1 & 54 & 32.9 & \\
\hline \multicolumn{6}{|l|}{ Marital status } \\
\hline Married & 153 & 73.6 & 55 & 26.4 & 0.78 \\
\hline Other & 136 & 72.3 & 52 & 27.7 & \\
\hline \multicolumn{6}{|l|}{ Economic class * } \\
\hline$A, B$, or $C$ & 232 & 70.7 & 96 & 29.3 & 0.03 \\
\hline D or E (low) & 57 & 83.8 & 11 & 16.2 & \\
\hline \multicolumn{6}{|l|}{ Arterial hypertension } \\
\hline Yes & 176 & 72.7 & 66 & 27.3 & 0.89 \\
\hline No & 113 & 73.4 & 41 & 26.6 & \\
\hline \multicolumn{6}{|l|}{ Diabetes } \\
\hline Yes & 55 & 78.6 & 15 & 21.4 & 0.25 \\
\hline No & 234 & 71.8 & 92 & 28.2 & \\
\hline \multicolumn{6}{|l|}{ Chronic lung disease } \\
\hline Yes & 52 & 77.6 & 15 & 22.4 & 0.35 \\
\hline No & 237 & 72.0 & 92 & 28.0 & \\
\hline \multicolumn{6}{|l|}{ Cardiovascular disease } \\
\hline Yes & 91 & 68.9 & 41 & 31.1 & 0.20 \\
\hline No & 198 & 75.0 & 66 & 25.0 & \\
\hline \multicolumn{6}{|c|}{ Hospitalization in previous year } \\
\hline Yes & 46 & 67.6 & 22 & 32.4 & 0.28 \\
\hline No & 243 & 74.1 & 85 & 25.9 & \\
\hline \multicolumn{6}{|l|}{ Last medical consultation } \\
\hline 1 year previously or less & 267 & 74.4 & 92 & 25.6 & 0.052 \\
\hline$\geq 1$ year previously & 22 & 59.5 & 15 & 40.5 & \\
\hline \multicolumn{6}{|l|}{ Place, medical appointment } \\
\hline Public healthcare unit ** & 147 & 75.4 & 48 & 24.6 & 0.29 \\
\hline Private practice only & 142 & 70.6 & 59 & 29.4 & \\
\hline \multicolumn{6}{|l|}{ Regular physical activity *** } \\
\hline Yes & 100 & 75.8 & 32 & 24.2 & 0.38 \\
\hline No & 189 & 71.6 & 75 & 28.4 & \\
\hline \multicolumn{6}{|l|}{ Smoking \# } \\
\hline Yes & 20 & 54.1 & 17 & 45.9 & 0.006 \\
\hline No & 269 & 74.9 & 90 & 25.1 & \\
\hline \multicolumn{6}{|l|}{ Daily alcohol consumption } \\
\hline Yes & 22 & 66.7 & 11 & 33.3 & 0.39 \\
\hline No & 267 & 73.6 & 96 & 26.4 & \\
\hline
\end{tabular}

* Brazilian Association of Market Research Companies (Critério de classificação econômica Brasil 2003. http://www.abep.org. br; accessed on 22/Sep/2006);

** Includes all subjects that reported habitually or sporadically using public healthcare services, regardless of having also used private medical services;

*** Any modality of physical exercise for 30 minutes or more, at least three times a week;

\# Currently smokes or stopped less than a year ago. 
Multivariate analysis of factors associated with influenza vaccine non-compliance. Londrina, Paraná State, Brazil, 2007.

\begin{tabular}{llcc}
\hline Factor & OR & 95\%Cl & P value \\
\hline Gender (female/male) & 1.60 & $0.98-2.60$ & 0.06 \\
Age $<70$ years & 1.95 & $1.21-3.15$ & 0.006 \\
Low economic class & 0.49 & $0.23-1.03$ & 0.06 \\
Low schooling & 0.81 & $0.49-1.34$ & 0.41 \\
Last medical consultation more than a year ago & 2.13 & $1.01-4.51$ & 0.047 \\
Smoking (smoker) & 2.40 & $1.16-4.94$ & 0.02 \\
\hline
\end{tabular}

95\% Cl: 95\% confidence interval; OR: odds ratio.

studies 20,21,22, so the gender variable was included in the multivariate model.

Among the unvaccinated elderly, some $80 \%$ explicitly manifested their wish not to receive the vaccine. An important share expressed fear of adverse events and lack of belief in the vaccine's efficacy or necessity. Another Brazilian study found these same reasons for non-compliance 23 , and similarmotiveswerereportedbyelderlysubjectsin developed countries like the United Kingdom 17,24, United States 25,26, and Switzerland 27.

Such claims and doubts could potentially be resolved if health professionals were to explain the vaccine properly to their elderly patients. However, few elderly subjects reported having received information on the vaccine from doctors or nurses. Such clarification, when it exists, has proven to be one of the main means to encourage vaccine uptake 17,24 . Other studies have already shown the limited participation by physicians in recommending the vaccine. According to one such study, with Brazilian physicians, $17.3 \%$ of the professionals from various specialties targeted in the study refused to participate, claiming that the vaccine was not one of their responsibilities 23,28 . This same study confirmed that prescription of the vaccine had still not been incorporated into routine medical practice, since only one-third of physicians prescribed it regularly.

This reality in medical practice is not specific to developing countries like Brazil, since it was also found in developed countries like the United States 29. In Switzerland, which shows low vaccination coverage rates against influenza, Humair et al. 30 showed an increase in coverage after a physician training program on the vaccine.

Although one of the main reasons claimed for non-compliance was fear of adverse events, the prevalence of the latter was low (6.6\%). Among the $13 \%$ of subjects that reported some symptom, half presented flu-like symptoms more than two weeks after vaccination (when it is unlikely that the symptoms were caused by the vaccine). Among the small percentage of elderly that reported flu-like symptoms less than two weeks after the vaccine, the possibility exists that such symptoms were caused by circulating viruses, thereby further lowering the real prevalence of adverse events.

Although symptoms appearing more than 48 hours after influenza vaccination cannot be classified as adverse events 7 , for the purposes of this study, symptoms presenting up to two weeks after vaccination were categorized as such. According to the answers obtained in the form, the elderly believe that adverse symptoms during this period are due to the vaccine, and the purpose of including these answers as adverse events was to estimate the prevalence of these responses. However, even considering the two-week period, the prevalence of adverse reactions was low.

Meanwhile, the period transpired between administering the vaccine and applying the questionnaire may have varied from a few days up to three months (since it depended on the date on which the individual was vaccinated and the date on which he or she was interviewed). Interviews held more than two weeks after vaccination may have produced difficulties in symptom recall, which would underestimate the prevalence of adverse events.

However, the prevalence of adverse events in the current study is consistent with the scientific literature as a whole, which also shows low prevalence of such events 23,28,31,32,33. One Brazilian study identified pain at the vaccination site as the most frequent event (12.6\%), followed by flu-like symptoms (7.8\%). However, in the current study the subjects were asked (with a closed question) whether they had experienced any symptoms like fever, pain at the vaccination site, and others 31. Lack of reports of pain in this study may 
have occurred due to difficulty by the elderly in recalling the symptom, or because neither the elderly nor the mass media appeared to consider it important.

The analysis showed a relevant percentage of the elderly that failed to receive the vaccine, and it is necessary to further elucidate the factors related to lack of vaccine uptake.

In the multivariate model, the variables "elderly subjects less than 70 years of age", "smoking", and "lack of a medical appointment in the previous year" were independently associated with non-compliance in relation to the other study variables.

As for age bracket, other Brazilian authors also found lower vaccine uptake among younger elderly individuals 14,16 . The same pattern has been shown elsewhere in the world, like the United States 34 and Sweden 35 . Perhaps these younger elderly rate their own health as good, and elderly with positive self-rated health are known to comply less with vaccination 24,25 .

Smokers are among the elderly with even better reasons for influenza vaccination, due to their increased likelihood of pulmonary complications. However, according to the current study, smokers showed a lower influenza vaccination rate than non-smokers. Nevertheless, another Brazilian study failed to show this association between smoking and non-compliance 14. A study in the United Kingdom, while not detecting a statistically significant association, showed a confidence interval mostly greater than 1 (95\%CI: 0.99-1.37) for the association between non-smoking and vaccine uptake 17.

As for the role of physician care favoring vaccine uptake, Lu et al. 34 found an association that agrees with the current study, i.e., individuals that report a medical consultation in the previous year were more prone to be vaccinated as compared to those without a consultation. A hypothesis for this finding is that individuals that are more concerned about their health tend to both see physicians more often and use other health resources, like vaccination. In addition, since they are closer to healthcare, they show higher odds of having more information and stimulus for vaccination than individuals reporting no contact with healthcare services in the previous year.

Thus, several studies have shown the doctor's explicit recommendation of the vaccine as an important factor for vaccine uptake $17,24,27$. It is important to highlight the physician's importance in promoting adherence. A more active attitude involving orientation and encouragement by these health professionals could increase the success of vaccination campaigns.
The role of nurses in promoting the vaccine should also be highlighted. Burns et al. 17 found an association between having received orientation on the need for (and adverse events associated with) the vaccine by nurses and physicians and greater uptake. In addition, in the current study, although the percentage of elderly that reported having obtained information on the vaccine from nurses was low, it was double the proportion that had received information from doctors. This highlights the urgent need for all health professionals, including community health agents, to become more involved in publicizing, encouraging, and providing orientation on the vaccine.

Schooling was not independently associated with the other variables in the multivariate model. This could be explained by its possible association with the other variables included in the model, like economic status. Another Brazilian study found an association between schooling and vaccine uptake, but economic status was not included as a variable in the model 15. Meanwhile, in developed countries like the United States, evidence indicates greater uptake by elderly with more schooling, possibly because they are more knowledgeable about health services 34 .

No association was found in this study between vaccination and systemic arterial hypertension or diabetes. Francisco et al. 16, studying two population groups from different municipalities, only found an association between vaccination and these two diseases in less populated municipalities. They raised the hypothesis that in these smaller communities, the population is more dependent on the public healthcare system and especially the medicines distributed by it, and is thus closer to the primary healthcare services and their recommendations. At any rate, groups of elderly with comorbidities like chronic obstructive pulmonary disease are particularly strong candidates for the vaccine 36 and need specific measures to improve their compliance.

As for the study's potential limitations, selfreported morbidity may have underestimated the prevalence of chronic non-transmissible diseases, due to difficulty by the elderly in reporting their own illnesses or even lack of diagnosis. However, the prevalence rates for systemic arterial hypertension and diabetes did not differ from those expected for this population 37 . With regard to obtaining data on alcohol consumption and smoking in this study, one cannot overlook the difficulties involved in the reliability of such data.

One helpful characteristic was the study design. Population-based studies can produce representative data on the study population, and 
household surveys are an appropriate method for this purpose. However, research with this type of design presents real difficulties. For reasons of security, people may fear that an interviewer will enter their homes and obtain information on their economic situation, health, family, and other sensitive personal information. This problem is illustrated by the refusals to participate in the study.

Finally, the results point to the need for elucidation of the low incidence of adverse events and real benefits of vaccination, thus combating myths on the influenza vaccine. Health professionals and the population should be made aware that the aim of the vaccine is not to decrease the incidence of flu-like symptoms, and that the vaccine is not effective for this purpose. The vaccine's real benefits should be publicized, including the prevention of complications and deaths from influenza, the impact on the occurrence of cardiovascular events, and the decrease in all-cause mortality. It is also necessary to elucidate the increase in the vaccine's efficacy with subsequent doses, i.e., with yearly revaccination.

The study also revealed the need for improvements in the vaccination campaigns, specifically for two different groups: elderly less than 70 years of age and elderly with higher influenza-related complication rates, like smokers. Thus, studies are needed to develop more specific wording and adjustment of the campaign for each less subgroup showing lower vaccine uptake.

More encouragement should be provided to health professionals to prescribe the vaccine and inform patients about it, since they are among the main actors in promoting vaccine uptake and the resulting benefits for quality of life among the elderly.

\section{Resumo}

A medida mais efetiva para evitar complicações da gripe é a vacinação. Os objetivos deste estudo de base populacional foram: estimar a cobertura vacinal contra a gripe em idosos não institucionalizados, analisar os fatores associados à não-adesão e identificar os eventos adversos pós-vacinais. A população de estudo foi constituída por idosos residentes em um município do Sul do Brasil. A amostra foi calculada em 425 idosos. Foram entrevistados 396 idosos, com idade entre $60 \mathrm{e}$ 95 anos. Embora 100\% dos idosos referissem conhecer a vacina, apenas 5,3\% referiram o médico como fonte da informação. Dentre os que não se vacinaram $83,2 \%$ alegaram como motivo da não-adesão o desejo explícito de não ser vacinado. As principais justificativas para isso foram o medo de eventos adversos e a falta de credibilidade na eficácia da vacina. A prevalência de eventos adversos foi baixa. Idade, tabagismo e ter referido ausência de consulta médica no último ano associaram-se a menor adesão. Evidenciou-se a necessidade de melhorias nas campanhas vacinais para idosos abaixo de 70 anos e idosos tabagistas.

Vacinas Contra Influenza; Cobertura Vacinal; Idoso

\section{Contributors}

R. M. Dip and M. A. S. Cabrera participated in drafting and revising the article.

\section{References}

1. Silvestre JA. O impacto da vacinação antiinfluenza na população idosa. In: Freitas EV, Py L, Neri AL, Cançado FAX, Gorzoni ML, Rocha SM, organizadores. Tratado de geriatria e gerontologia. Rio de Janeiro: Editora Guanabara Koogan; 2002. p. 56973.

2. Forleo Neto E, Halker E, Santos VJ, Paiva TM, Toniolo Neto J. Influenza. Rev Soc Bras Med Trop 2003; 36:267-74.

3. Nguyen-Van-Tam JS, Hampson AW. The epidemiology and clinical impact of pandemic influenza. Vaccine 2003; 21:1762-8.

4. Thompson WW, Shay DK, Weintraub E, Brammer L, Bridges CB, Cox N, et al. Influenza-associated hospitalizations in the United States. JAMA 2004; 292:1333-40.

5. Thompson WW, Shay DK, Weintraub E, Brammer L, Cox N, Anderson LJ, et al. Mortality associated with influenza and respiratory syncytial virus in the United States. JAMA 2003; 289:179-86.

6. Demicheli V, Jefferson T, Rivetti D, Deeks J. Prevention and early treatment of influenza in healthy adults. Vaccine 2000; 18:957-1030.

7. Fiore AE, Shay DK, Haber P, Iskander JK, Uyeki TM, Mootrey G, et al. Prevention and control of influenza. Recommendations of the Advisory Committee on Immunization Practices (ACIP), 2007. MMWR Recomm Rep 2007; 56(RR-6):1-54. 
8. Donalísio MR. Política brasileira de vacinação contra a influenza e seu impacto sobre a saúde do idoso. Cad Saúde Pública 2007; 23:494-5.

9. Advisory Committee on Immunization Practices, Smith NM, Bresee JS, Shay DK, Uyeki TM, Cox NJ, et al. Prevention and Control of Influenza: recommendations of the Advisory Committee on Immunization Practices (ACIP). MMWR Recomm Rep 2006; 55(RR-10):1-42.

10. Jefferson T, Rivetti D, Rudin M, Di Pietrantonj C, Demicheli V. Efficacy and effectiveness of influenza vaccines in elderly people: a systematic review. Lancet 2005; 366:1165-74.

11. Nichol KL, Nordin J, Mullooly J, Lask R, Fillbrandt $\mathrm{K}$, Iwane $\mathrm{M}$. Influenza vaccination and reduction in hospitalizations for cardiac disease and stroke among the elderly. N Engl J Med 2003; 348:1322-32.

12. Eurich DT, Marrie TJ, Johnstone J, Majumdar SR Mortality reduction with influenza vaccine in patients with pneumonia outside "flu" season. Am J Respir Crit Care Med 2008; 178:527-33.

13. Jackson ML, Nelson JC, Weiss NS, Neuzil KM, Barlow W, Jackson LA. Influenza vaccination and risk of community-acquired pneumonia in immunocompetent elderly people: a population-based, nested case-control study. Lancet 2008; 372:398-405.

14. Donalísio MR, Ruiz T, Cordeiro R. Fatores associados à vacinação contra influenza em idosos em município do Sudeste do Brasil. Rev Saúde Pública 2006; 40:115-9.

15. Francisco PMSB, Donalísio MR, Barros MBA, César CLG, Carandina L, Goldbaum M. Fatores associados à vacinação contra a influenza em idosos. Rev Panam Salud Pública 2006; 19:259-64.

16. Francisco PMSB, Donalísio MR, Barros MBA, César CLG, Carandina L, Goldbaum M. Vacinação contra influenza em idosos por área de residência: prevalência e fatores associados. Rev Bras Epidemiol 2006; 9:162-71.

17. Burns VE, Ring C, Carroll D. Factors influencing vaccination uptake in an elderly, communitybased sample. Vaccine 2005; 23:3604-8.

18. Instituto Brasileiro de Geografia e Estatística. Base de informações por setor censitário: Censo Demográfico 2000. Resultados do universo [CD-ROM] Rio de Janeiro: Instituto Brasileiro de Geografia e Estatística; 2000.

19. MacDonald R, Baken L, Nelson A, Nichol KL. Validation of self-report of influenza and pneumococcal vaccination status in elderly outpatients. Am J Prev Med 1999; 16:173-7.

20. Borrell C, García-Calvente MM, Martí-Bosca JV. La salud pública desde la perspectiva de género y clase social. Gac Sanit 2004; 18 Suppl 1:2-6.

21. Artazcoz L. Las desigualdades de género en salud en la agenda de salud pública. Gac Sanit 2004; 18 Suppl 2:1-2.

22. Dentom M, Prus S, Walters V. Gender differences in health: a Canadian study of the psychosocial, structural and behavioural determinants of health. Soc Sci Med 2004; 58:2585-600.

23. Moura M, Silva LJ. Pesquisa de opinião sobre as campanhas de vacinação contra a influenza no estado de São Paulo. Boletim Epidemiológico Paulista $2004 ; 1: 8-10$.
24. Mangtani P, Breeze E, Stirling S, Hanciles S, Kovats $\mathrm{S}$, Fletcher A. Cross-sectional survey of older peoples' views related to influenza vaccine uptake. BMC Public Health 2006; 6:249.

25. van Essen GA, Kuyvenhoven MM, Melker RA. Why do healthy elderly people fail to comply with influenza vaccination? Age Ageing 1997; 26:275-9.

26. Santibanez TA, Nowalk MP, Zimmerman RK, Jewell IK, Bardella IJ, Wilson SA, et al. Knowledge and beliefs about influenza, pneumococcal disease, and immunizations among older people. J Am Geriatr Soc 2002; 50:1711-6.

27. Bovier PA, Chamot E, Gallacchi MB, Loutan L. Importance of patients' perceptions and general practitioners' recommendations in understanding missed opportunities for immunisations in Swiss adults. Vaccine 2001; 19:4760-7.

28. Centro de Referência em Saúde do Trabalhador de São Paulo, Secretaria do Estado de São Paulo. Pesquisas indicam pequena participação dos médicos no incentivo à vacina contra a influenza. Rev Saúde Pública 2004; 38:607-8.

29. Nichol KL, Zimmerman R. Generalist and subspecialist physician's knowledge, attitudes, and practices regarding influenza and pneumococcal vaccinations for elderly and other high-risk patients. Arch Intern Med 2001; 161:2702-8.

30. Humair JP, Buchs CR, Stalder H. Promoting influenza vaccination of elderly patients in primary care. Fam Pract 2002; 19:383-9.

31. Donalísio MR, Ramalheira RM, Cordeiro R. Eventos adversos após a vacinação contra a influenza em idosos, Distrito de Campinas, SP, 2000. Rev Soc Bras Med Trop 2003; 36:467-71.

32. Perucchini E, Consonni S, Sandrini MC, Bergamaschini L, Vergani C. Adverse reactions to influenza vaccine alone or with pneumococcal vaccine in the elderly. J Am Geriatr Soc 2004; 52:1219-20.

33. Margolis KL, Poland GA, Nichol KL, MacPherson DS, Meyer JD, Korn JE, et al. Frequency of adverse reactions after influenza vaccination. Am J Med 1990; 88:27-30.

34. Lu PJ, Singleton JA, Rangel MC, Wortley PM, Bridges CB. Influenza vaccination trends among adults 65 years or older in the United States, 1989-2002. Arch Intern Med 2005; 165:1849-56.

35. Kroneman MW, van Essen G. Variations in influenza vaccination coverage among the high-risk population in Sweden in 2003/4 and 2004/5: a population survey. BMC Public Health 2007; 7:113.

36. Gomes L. Fatores de risco e medidas profiláticas nas pneumonias adquiridas na comunidade. J Pneumol 2001; 27:97-114.

37. Cabrera MAS, Jacob Filho W. Obesidade em idosos: prevalência, distribuição e associação com hábitos e co-morbidades. Arq Bras Endocrinol Metab 2001; 45:494-501.

Submitted on 22/Dec/2008

Final version resubmitted on 21/Jun/2009

Approved on 09/Sep/2009 